\title{
EXAMINING THE ACCURACY OF POSITIONING USING SELECTED SMARTPHONE APPLICATIONS
}

\author{
Natalia Kuboń, Marek Plewako
}

\section{Summary}

The paper presents the results of situational measurements of 6 points of a test grid in twodimensional space. Measurements were made using 8 selected smartphone applications: Precise GPS, MapIt, Turbo GPS, Coordinator +, GPS Test, Precision GPS Free, GGRS87, and Mobile Topographer. Based on the $\Delta x$ and $\Delta y$ values obtained as differences in measurement results and reference coordinates, it was possible to determine that the mean values of these differences remain at the level of $\pm 2 \mathrm{~m}$, although individual differences assume smaller and larger values. One of the applications generated the results classified in the error theory as errors of gross type.

\section{Keywords}

GPS phone applications $\bullet$ accuracy of positioning $\bullet$ satellite navigation

\section{Introduction}

The major role played by satellite navigation in the modern world also brings many questions related to, for instance, the viability of its application for the performance of specific tasks. The turbulent development of mobile communication technology has resulted in the emergence of smartphone applications, which make it possible, among other things, to determine the location of the given phone device in the global spatial reference system with a specific degree of accuracy.

There are a large number of (both fee-based and free-of-charge) navigational smartphone applications, offered by various developers and providers. In most of the names of these applications, the GPS acronym is included. The questions about the accuracy of determining the position, and about the reliability of the given application, seem to be pertinent. The subject has an aspect of novelty, which is confirmed by the lack of available literature referring thereto.

\section{Satellite Navigation System with a single receiver L1. Study method}

Global Satellite Navigation Systems (GNSS) cover the entire Earth with their range. One of these is the most popular American (US) GPS system. The receiver registers signals from a minimum of 4 satellites, whose positions are well known. Thanks to the software, it is possible to determine, in real time, the position of the receiver, and to adjust its clock. 
GPS signals are transmitted on the basic carrier wave frequencies L1 and L2. The receiver placed in the smartphone determines its position on the basis of the C/A code, L1 frequency, and the support system, for instance, the EGNOS. The horizontal accuracy of position determination ranges from a few to a dozen or so meters with a confidence level of 95\% [Kruszewski 2016].

From among numerous free smartphone applications offered on the market for test measurement, 8 were selected. Test grid consisting of 6 points was measured using the static GPS method, in relation to the KRAW reference station in the ASG - EUPOS system. The accuracy of these points is determined to be $\pm 2-3 \mathrm{~mm}$. Coordinates $x, y$ of these points were found to be error-free with respect to the accuracy of determining the position of the said points by means of smartphone applications.

\section{Field measurements}

Measurement conducted using smartphone applications took place on 5 November 2016, between 11:00 and 13:00. At the time it was sunny, with temperature around $12^{\circ} \mathrm{C}$. The Lenovo TAB 2 A7 tablet with Android was used for the purpose. 6 points $(2041,2042$, 2043, 2044, 2045 and 2046) of known coordinates were measured using eight applications, that is: Precise GPS, MapIt, Turbo GPS, Coordinator+, GPS Test, Precision GPS Free, GGRS87, and Mobile Topographer. Each single measurement lasted about 1 minute.

\subsection{Description of the area}

The measured points (Fig. 1) are located on a grassy meadow at the Faculty of Environmental Engineering and Geodesy of the University of Agriculture in Krakow, at Balicka street, number 253C. The area on which the points are located is slightly ridged, but it is not difficult to measure.

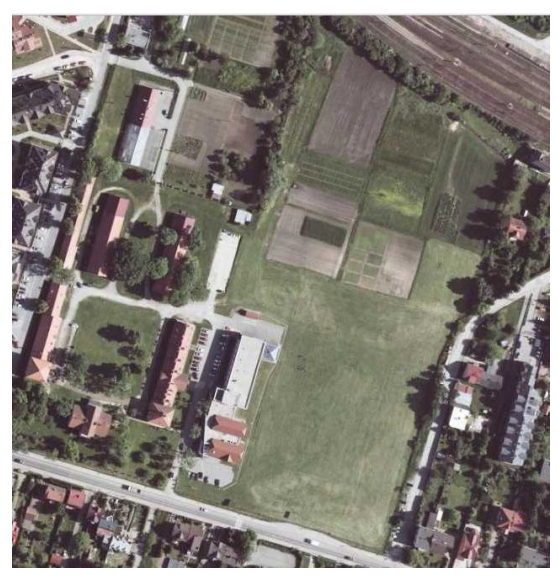

Source: Geoportal, http://mapy.geoportal.gov.pl/imap/?gpmap=gp0\&actions=acShowWgButtonPanel_kraj_ORTO]

Fig. 1. Location of the points 


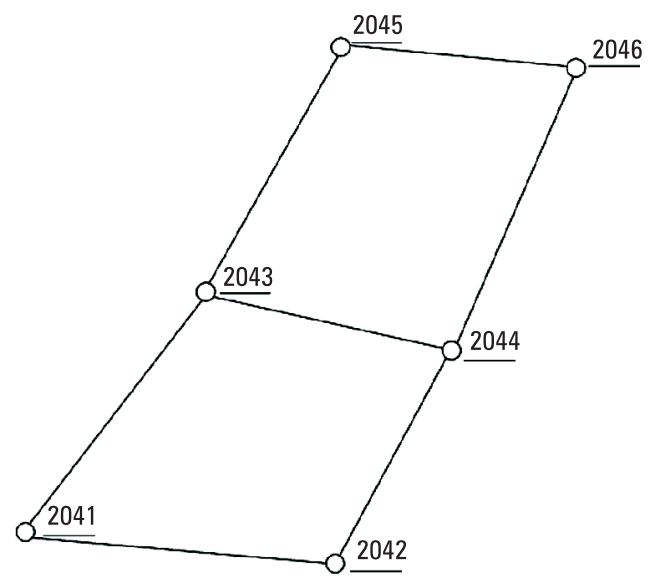

Fig. 2. Distribution of the points

The points form a shape approximating a rectangle (Fig. 2). They have been placed fairly evenly throughout the given area.

Table 1. Measurement of the coordinates using GPS

\begin{tabular}{|c|c|c|c|c|c|c|}
\hline \multirow{2}{*}{$\begin{array}{c}\text { Point } \\
\text { number }\end{array}$} & \multicolumn{3}{|c|}{ B } & \multicolumn{3}{|c|}{$\mathrm{L}$} \\
\hline & {$\left[^{\circ}\right]$} & ['] & ["] & {$\left[{ }^{\circ}\right]$} & ['] & [”] \\
\hline 2041 & 50 & 4 & 57.461682 & 19 & 51 & 9.105473 \\
\hline 2042 & 50 & 4 & 56.372201 & 19 & 51 & 15.318107 \\
\hline 2043 & 50 & 5 & 1.988256 & 19 & 51 & 11.790754 \\
\hline 2044 & 50 & 5 & 0.326484 & 19 & 51 & 17.082849 \\
\hline 2045 & 50 & 5 & 6.451985 & 19 & 51 & 14.436776 \\
\hline 2046 & 50 & 5 & 4.292838 & 19 & 51 & 18.852632 \\
\hline $\begin{array}{c}\text { Point } \\
\text { number }\end{array}$ & \multicolumn{3}{|c|}{$X[\mathrm{~m}]$} & \multicolumn{3}{|c|}{$Y[\mathrm{~m}]$} \\
\hline 2041 & \multicolumn{3}{|c|}{5550241.150} & \multicolumn{3}{|c|}{7417879.597} \\
\hline 2042 & \multicolumn{3}{|c|}{5550205.595} & \multicolumn{3}{|c|}{7418002.582} \\
\hline 2043 & \multicolumn{3}{|c|}{5550380.174} & \multicolumn{3}{|c|}{7417935.124} \\
\hline 2044 & \multicolumn{3}{|c|}{5550327.221} & \multicolumn{3}{|c|}{7418039.537} \\
\hline 2045 & \multicolumn{3}{|c|}{5550517.268} & \multicolumn{3}{|c|}{7417989.839} \\
\hline 2046 & \multicolumn{3}{|c|}{5550449.218} & \multicolumn{3}{|c|}{7418076.596} \\
\hline
\end{tabular}

Source: data made available from the University's resources 
The data obtained (Table 1 ) for the $\mathrm{B}$ and $\mathrm{L}$ coordinates of the points were measured using GPS technology by relating to the ASG-EUPOS KRAW reference station. Then they were transposed in the Transpol v 2.06 software to the "2000" layout. Their accuracy remains within the range of $2-3 \mathrm{~mm}$.

\subsection{Characteristics of selected applications, and presentation of measurement results}

All applications come from the Google Play store, and they are free for all users.

\subsubsection{Precise GPS}

The application increases the precision of coordinate measurement by repeatedly activating the sensor in order to balance the received data. In order to achieve better accuracy, at least 30-50 independent measurements should be taken. Depending on the type of GPS sensor and satellite system, the results obtained may vary [https://play. google.com/store/apps/details?id=precise.GPS.free\&hl=en]

Table 2. Measurement of the coordinates using the Precise GPS application

\begin{tabular}{|c|c|c|c|c|c|c|}
\hline \multirow{2}{*}{$\begin{array}{l}\text { Point } \\
\text { number }\end{array}$} & \multicolumn{3}{|c|}{ B } & \multicolumn{3}{|c|}{$\mathrm{L}$} \\
\hline & {$\left[{ }^{\circ}\right]$} & ['] & ["] & {$\left[{ }^{\circ}\right]$} & ['] & [”] \\
\hline 2041 & 50 & 4 & 57.461688 & 19 & 51 & 9.10800 \\
\hline 2042 & 50 & 4 & 56.42400 & 19 & 51 & 15.30000 \\
\hline 2043 & 50 & 5 & 2.06412 & 19 & 51 & 11.83212 \\
\hline 2044 & 50 & 5 & 0.40812 & 19 & 51 & 17.08200 \\
\hline 2045 & 50 & 5 & 6.51588 & 19 & 51 & 14.40000 \\
\hline 2046 & 50 & 5 & 4.40988 & 19 & 51 & 18.90612 \\
\hline $\begin{array}{l}\text { Point } \\
\text { number }\end{array}$ & \multicolumn{3}{|c|}{$X[\mathrm{~m}]$} & \multicolumn{3}{|c|}{$Y[\mathrm{~m}]$} \\
\hline 2041 & \multicolumn{3}{|c|}{5550241.156} & \multicolumn{3}{|c|}{7417879.647} \\
\hline 2042 & \multicolumn{3}{|c|}{5550207.201} & \multicolumn{3}{|c|}{7418002.246} \\
\hline 2043 & \multicolumn{3}{|c|}{5550382.504} & \multicolumn{3}{|c|}{7417935.982} \\
\hline 2044 & \multicolumn{3}{|c|}{5550329.742} & \multicolumn{3}{|c|}{7418039.558} \\
\hline 2045 & \multicolumn{3}{|c|}{5550519.254} & \multicolumn{3}{|c|}{7417989.139} \\
\hline 2046 & \multicolumn{3}{|c|}{5550452.818} & \multicolumn{3}{|c|}{7418077.714} \\
\hline
\end{tabular}

Table 2 presents the measurements made using the Precise GPS application in the form of coordinates B, L then transformed into $X, Y$ coordinates in the "2000" system, also shown. 


\subsubsection{MapIt}

MapIt is an application whose task is to assist in collecting GPS data, such as for instance satellite status, or location. It can also be used to measure and calculate distance or area size. It is possible to import and export data [https:/play.google.com/store/apps/ details?id=com.osedok.gisdatacollector\&hl=en]

Table 3. Measurement of the coordinates using the MapIt application

\begin{tabular}{|c|c|c|c|c|c|c|}
\hline \multirow{2}{*}{$\begin{array}{l}\text { Point } \\
\text { number }\end{array}$} & \multicolumn{3}{|c|}{ B } & \multicolumn{3}{|c|}{$\mathrm{L}$} \\
\hline & {$\left[^{\circ}\right]$} & ['] & [”] & {$\left[^{\circ}\right]$} & {$\left[{ }^{\prime}\right]$} & ["] \\
\hline 2041 & 50 & 4 & 57.4608 & 19 & 51 & 9.1080 \\
\hline 2042 & 50 & 4 & 56.4240 & 19 & 51 & 15.3000 \\
\hline 2043 & 50 & 5 & 2.0652 & 19 & 51 & 11.8332 \\
\hline 2044 & 50 & 5 & 0.4380 & 19 & 51 & 17.0748 \\
\hline 2045 & 50 & 5 & 6.5148 & 19 & 51 & 14.4000 \\
\hline 2046 & 50 & 5 & 4.4088 & 19 & 51 & 18.9072 \\
\hline $\begin{array}{l}\text { Point } \\
\text { number }\end{array}$ & \multicolumn{3}{|c|}{$X[\mathrm{~m}]$} & \multicolumn{3}{|c|}{$Y[\mathrm{~m}]$} \\
\hline 2041 & \multicolumn{3}{|c|}{5550241.122} & \multicolumn{3}{|c|}{7417879.646} \\
\hline 2042 & \multicolumn{3}{|c|}{5550207.201} & \multicolumn{3}{|c|}{7418002.246} \\
\hline 2043 & \multicolumn{3}{|c|}{5550382.538} & \multicolumn{3}{|c|}{7417936.005} \\
\hline 2044 & \multicolumn{3}{|c|}{5550330.668} & \multicolumn{3}{|c|}{7418039.429} \\
\hline 2045 & \multicolumn{3}{|c|}{5550519.220} & \multicolumn{3}{|c|}{7417989.138} \\
\hline 2046 & \multicolumn{3}{|c|}{5550452.784} & \multicolumn{3}{|c|}{7418077.735} \\
\hline
\end{tabular}

The table 3 above shows the measurements made with the MapIt application in the form of coordinates B, L then transformed to the coordinates X, Y in the " 2000 " system.

\subsubsection{Turbo GPS}

This particular application makes it possible to determine the position, and it provides the so-called street view. In addition, it can support an external Bluetooth GPS, and it contains maps with directions. It is possible to import and export files [https://play. google.com/store/apps/details?id=com.turboirc.tgps.v2015\&hl=en] 
Table 4. Measurement of the coordinates using the Turbo GPS application

\begin{tabular}{|c|c|c|c|c|c|c|}
\hline \multirow{2}{*}{$\begin{array}{c}\text { Point } \\
\text { number }\end{array}$} & \multicolumn{3}{|c|}{ B } & \multicolumn{3}{|c|}{$\mathrm{L}$} \\
\hline & {$\left[{ }^{\circ}\right]$} & ['] & ["] & [ $\left.{ }^{\circ}\right]$ & ['] & ["] \\
\hline 2041 & 50 & 4 & 57.4608 & 19 & 51 & 9.1080 \\
\hline 2042 & 50 & 4 & 56.4240 & 19 & 51 & 15.3000 \\
\hline 2043 & 50 & 5 & 2.0652 & 19 & 51 & 11.8332 \\
\hline 2044 & 50 & 5 & 0.4380 & 19 & 51 & 17.0748 \\
\hline 2045 & 50 & 5 & 6.5148 & 19 & 51 & 14.4000 \\
\hline 2046 & 50 & 5 & 4.4088 & 19 & 51 & 18.9072 \\
\hline $\begin{array}{c}\text { Point } \\
\text { number }\end{array}$ & \multicolumn{3}{|c|}{$X[\mathrm{~m}]$} & \multicolumn{3}{|c|}{$Y[\mathrm{~m}]$} \\
\hline 2041 & \multicolumn{3}{|c|}{5550241.122} & \multicolumn{3}{|c|}{7417879.646} \\
\hline 2042 & \multicolumn{3}{|c|}{5550207.201} & \multicolumn{3}{|c|}{7418002.246} \\
\hline 2043 & \multicolumn{3}{|c|}{5550382.538} & \multicolumn{3}{|c|}{7417936.005} \\
\hline 2044 & \multicolumn{3}{|c|}{5550330.668} & \multicolumn{3}{|c|}{7418039.429} \\
\hline 2045 & \multicolumn{3}{|c|}{5550519.220} & \multicolumn{3}{|c|}{7417989.138} \\
\hline 2046 & \multicolumn{3}{|c|}{5550452.784} & \multicolumn{3}{|c|}{7418077.735} \\
\hline
\end{tabular}

Table 4 presents the measurements conducted using the Turbo GPS application, in the form of coordinates B, L then transformed to coordinates $X, Y$ in the "2000" system.

\subsubsection{Coordinator+}

This is an application created by a Turkish company. The software allows the user to measure coordinates in the selected coordinate system. In addition, it provides information about the distance, as well as the difference between the points on the map. It also makes it possible to convert coordinates from one coordinate system to another [https:// play.google.com/store/apps/details?id=com.suleymaner.coordinatorplus\&hl=en]

Table 5. Measurement of the coordinates using the Coordinator+ application

\begin{tabular}{|c|c|c|c|c|c|c|}
\hline \multirow{2}{*}{$\begin{array}{c}\text { Point } \\
\text { number }\end{array}$} & \multicolumn{3}{|c|}{ B } & \multicolumn{3}{c|}{ L } \\
\cline { 2 - 7 } & {$\left[{ }^{\circ}\right]$} & {$\left[{ }^{\circ}\right]$} & {$\left[{ }^{\prime \prime}\right]$} & {$\left[^{\circ}\right]$} & {$\left[{ }^{\prime}\right]$} & {$\left[{ }^{\prime \prime}\right]$} \\
\hline 2041 & 50 & 4 & 57.461988 & 19 & 51 & 9.108000 \\
\hline 2042 & 50 & 4 & 56.424000 & 19 & 51 & 15.300000 \\
\hline 2043 & 50 & 5 & 2.063976 & 19 & 51 & 11.831976 \\
\hline 2044 & 50 & 5 & 0.438000 & 19 & 51 & 17.075988 \\
\hline 2045 & 50 & 5 & 6.515988 & 19 & 51 & 14.400000 \\
\hline 2046 & 50 & 5 & 4.409988 & 19 & 51 & 18.905976 \\
\hline
\end{tabular}




\begin{tabular}{|c|c|c|}
\hline $\begin{array}{c}\text { Point } \\
\text { number }\end{array}$ & $X[\mathrm{~m}]$ & $Y[\mathrm{~m}]$ \\
\hline 2041 & 5550241.159 & 7417879.647 \\
\hline 2042 & 5550207.201 & 7418002.246 \\
\hline 2043 & 5550382.501 & 7417935.980 \\
\hline 2044 & 5550330.668 & 7418039.453 \\
\hline 2045 & 5550519.257 & 7417989.139 \\
\hline 2046 & 5550452.821 & 7418077.712 \\
\hline
\end{tabular}

Table 5 presents the measurements conducted using the Coordinator+ application, in the form of coordinates B, L then transformed to coordinates $X, Y$ in the " 2000 " system.

\subsubsection{GPS Test}

This application shows the current location in text format as well as visually on the map; it also shows GPS signal in the form of a bar graph, the placement of satellites in the sky, the current altitude, location and speed, and the current GPS reading time [https://play.google.com/store/apps/details?id=com.chartcross.gpstest\&hl=en]

Table 6. Measurement of the coordinates using the GPS Test application

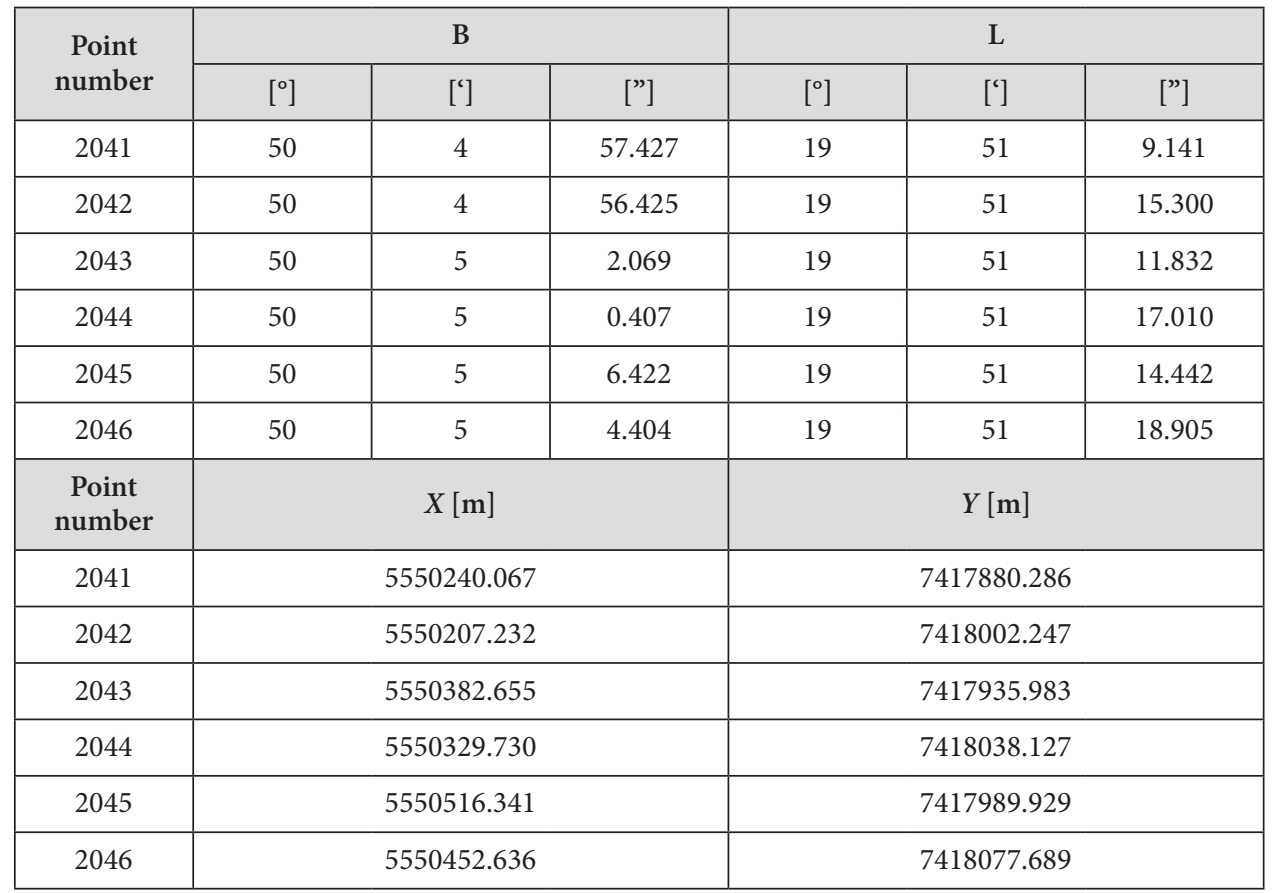


Table 6 presents the measurements conducted using the GPS System application, in the form of coordinates B, L, and transformed coordinates $X, Y$ in the "2000" system.

\subsubsection{Precision GPS Free}

The application uses a GPS sensor in order to determine the exact position. It calculates the weighted average for a given measurement. The longer the measurement takes, the better accuracy is obtained. It is not possible to record points [https://play.google.com/ store/apps/details?id=com.sciencewithandroid.precisiongpsfree\&hl=en]

Table 7. Measurement of the coordinates using the Precision GPS Free application

\begin{tabular}{|c|c|c|c|c|c|c|}
\hline \multirow{2}{*}{$\begin{array}{c}\text { Point } \\
\text { number }\end{array}$} & \multicolumn{3}{|c|}{ B } & \multicolumn{3}{|c|}{$\mathrm{L}$} \\
\hline & [ $\left.{ }^{\circ}\right]$ & ['] & ["] & {$\left[^{\circ}\right]$} & ['] & [”] \\
\hline 2041 & 50 & 4 & 57.4070 & 19 & 51 & 9.1094 \\
\hline 2042 & 50 & 4 & 56.4200 & 19 & 51 & 15.0000 \\
\hline 2043 & 50 & 5 & 0.3189 & 19 & 51 & 17.0836 \\
\hline 2044 & 50 & 5 & 2.0600 & 19 & 51 & 11.8300 \\
\hline 2045 & 50 & 5 & 6.4730 & 19 & 51 & 14.3577 \\
\hline 2046 & 50 & 5 & 4.4000 & 19 & 51 & 18.9000 \\
\hline $\begin{array}{c}\text { Point } \\
\text { number }\end{array}$ & \multicolumn{3}{|c|}{$X[\mathrm{~m}]$} & \multicolumn{3}{|c|}{$Y[\mathrm{~m}]$} \\
\hline 2041 & \multicolumn{3}{|c|}{5550239.459} & \multicolumn{3}{|c|}{7417879.649} \\
\hline 2042 & \multicolumn{3}{|c|}{5550207.169} & \multicolumn{3}{|c|}{7417996.281} \\
\hline 2043 & \multicolumn{3}{|c|}{5550326.986} & \multicolumn{3}{|c|}{7418039.548} \\
\hline 2044 & \multicolumn{3}{|c|}{5550382.378} & \multicolumn{3}{|c|}{7417935.939} \\
\hline 2045 & \multicolumn{3}{|c|}{5550517.942} & \multicolumn{3}{|c|}{7417988.278} \\
\hline 2046 & \multicolumn{3}{|c|}{5550452.514} & \multicolumn{3}{|c|}{7418077.588} \\
\hline
\end{tabular}

Table 7 presents measurements made with the Precision GPS Free application in the form of B, L coordinates as well as transformed X, Y coordinates in the " 2000 " system.

\subsubsection{GGRS87}

The GGRS87 application is designed to increase the accuracy of GPS. It provides the function to record points, and to calculate the area size. It allows the user to export files [https://play.google.com/store/apps/details?id=gr.stasta.egsa\&hl=en] 
Table 8. Measurement of the coordinates using the GGRS87 application

\begin{tabular}{|c|c|c|c|c|c|c|}
\hline \multirow{2}{*}{$\begin{array}{c}\text { Point } \\
\text { number }\end{array}$} & \multicolumn{3}{|c|}{ B } & \multicolumn{3}{|c|}{$\mathrm{L}$} \\
\hline & {$\left[^{\circ}\right]$} & ['] & ["] & {$\left[^{\circ}\right]$} & {$\left[{ }^{\prime}\right]$} & [”] \\
\hline 2041 & 50 & 4 & 57.786672 & 19 & 51 & 9.1080 \\
\hline 2042 & 50 & 4 & 56.424000 & 19 & 51 & 15.3000 \\
\hline 2043 & 50 & 5 & 2.064012 & 19 & 51 & 11.8332 \\
\hline 2044 & 50 & 5 & 0.402000 & 19 & 51 & 17.0748 \\
\hline 2045 & 50 & 5 & 6.497988 & 19 & 51 & 14.4000 \\
\hline 2046 & 50 & 5 & 4.409988 & 19 & 51 & 18.9072 \\
\hline $\begin{array}{c}\text { Point } \\
\text { number }\end{array}$ & \multicolumn{3}{|c|}{$X[\mathrm{~m}]$} & \multicolumn{3}{|c|}{$Y[\mathrm{~m}]$} \\
\hline 2041 & \multicolumn{3}{|c|}{5550241.122} & \multicolumn{3}{|c|}{7417877.231} \\
\hline 2042 & \multicolumn{3}{|c|}{5550207.201} & \multicolumn{3}{|c|}{7418002.246} \\
\hline 2043 & \multicolumn{3}{|c|}{5550382.538} & \multicolumn{3}{|c|}{7417935.980} \\
\hline 2044 & \multicolumn{3}{|c|}{5550330.668} & \multicolumn{3}{|c|}{7418039.556} \\
\hline 2045 & \multicolumn{3}{|c|}{5550519.220} & \multicolumn{3}{|c|}{7417990.800} \\
\hline 2046 & \multicolumn{3}{|c|}{5550452.784} & \multicolumn{3}{|c|}{7418077.712} \\
\hline
\end{tabular}

Table 8 presents measurements made with the GGRS87 application in the form of B, L coordinates as well as transformed X, Y coordinates in the " 2000 " system.

\subsubsection{Mobile Topographer}

This application, by calibrating the map, the weighted average, as well as calibrating the devices on the map, aims to increase the accuracy of GPS. In addition, it provides the ability to convert data into various coordinate systems. It shows the position of the satellites in the sky as well as their signal strength. It guides the user to the selected location, and also enables the calculation of area size and ellipsoidal height [https:// play.google.com/store/apps/details?id=gr.stasta.mobiletopographer\&hl=en] 
Table 9. Measurement of the coordinates using the Mobile Topographer application

\begin{tabular}{|c|c|c|c|c|c|c|}
\hline \multirow{2}{*}{$\begin{array}{l}\text { Point } \\
\text { number }\end{array}$} & \multicolumn{3}{|c|}{ B } & \multicolumn{3}{|c|}{$\mathrm{L}$} \\
\hline & {$\left[^{\circ}\right]$} & ['] & ["] & {$\left[{ }^{\circ}\right]$} & ['] & [”] \\
\hline 2041 & 50 & 4 & 57.456012 & 19 & 51 & 9.065988 \\
\hline 2042 & 50 & 4 & 56.424000 & 19 & 51 & 15.300000 \\
\hline 2043 & 50 & 5 & 2.064012 & 19 & 51 & 11.832012 \\
\hline 2044 & 50 & 5 & 0.402000 & 19 & 51 & 17.082000 \\
\hline 2045 & 50 & 5 & 6.515988 & 19 & 51 & 14.436792 \\
\hline 2046 & 50 & 5 & 4.409988 & 19 & 51 & 18.906012 \\
\hline $\begin{array}{c}\text { Point } \\
\text { number }\end{array}$ & \multicolumn{3}{|c|}{$X[\mathrm{~m}]$} & \multicolumn{3}{|c|}{$Y[\mathrm{~m}]$} \\
\hline 2041 & \multicolumn{3}{|c|}{5550240.986} & \multicolumn{3}{|c|}{7417878.809} \\
\hline 2042 & \multicolumn{3}{|c|}{5550207.201} & \multicolumn{3}{|c|}{7418002.246} \\
\hline 2043 & \multicolumn{3}{|c|}{5550382.501} & \multicolumn{3}{|c|}{7417935.980} \\
\hline 2044 & \multicolumn{3}{|c|}{5550329.554} & \multicolumn{3}{|c|}{7418039.556} \\
\hline 2045 & \multicolumn{3}{|c|}{5550519.246} & \multicolumn{3}{|c|}{7417989.870} \\
\hline 2046 & \multicolumn{3}{|c|}{5550452.821} & \multicolumn{3}{|c|}{7418077.712} \\
\hline
\end{tabular}

Table 9 presents the measurements made using the Mobile Topographer application in the form of B, L coordinates and the transformed X, Y coordinates in the " 2000 " system.

\subsection{Comparison of data from GPS measurement with smartphone applications}

Measurements made using various applications have been compiled with the available coordinates that had been obtained using a static method (Table 1). In the present study, only an sample set of results for one of the designated points will be presented, as well as averages for 6 points of the $X$ and $Y$ coordinate difference values for each of the 8 tested applications.

\subsubsection{Presentation of the value of difference at point 2044}

At point 2044 (Fig. 3), the tested applications reached the values of the difference from approx. $0.020 \mathrm{~m}$ to approx. $104.000 \mathrm{~m}$. For $X$ coordinates, GGRS87 and Mobile Topographer applications presented the smallest values of differences $(2.333 \mathrm{~m})$. The GPS Test obtained an accuracy of $2.510 \mathrm{~m}$, and Precise GPS, $2.522 \mathrm{~m}$. Coordinator+ reached the value of $3.447 \mathrm{~m}$ difference, with MapIt and Turbo GPS at $3.448 \mathrm{~m}$. The biggest difference was observed in the Precision GPS Free application. For $Y$ coordi- 
nates, the smallest difference was $0.019 \mathrm{~m}$, which was recorded for the GGRS87 and Mobile Topographer applications. The applications, which also obtained the values of the difference below one meter, include: Precise GPS $(0.022 \mathrm{~m})$, Coordinator+ $(0.083 \mathrm{~m})$, MapIt, and Turbo GPS $(0.107 \mathrm{~m})$. The worst accuracy was obtained by Precision GPS Free, at $103.598 \mathrm{~m}$. As demonstrated, the best results were obtained from the GGR87 application and the Mobile Topographer application, and the worst results came from the Precision GPS Free [Kuboń 2017].

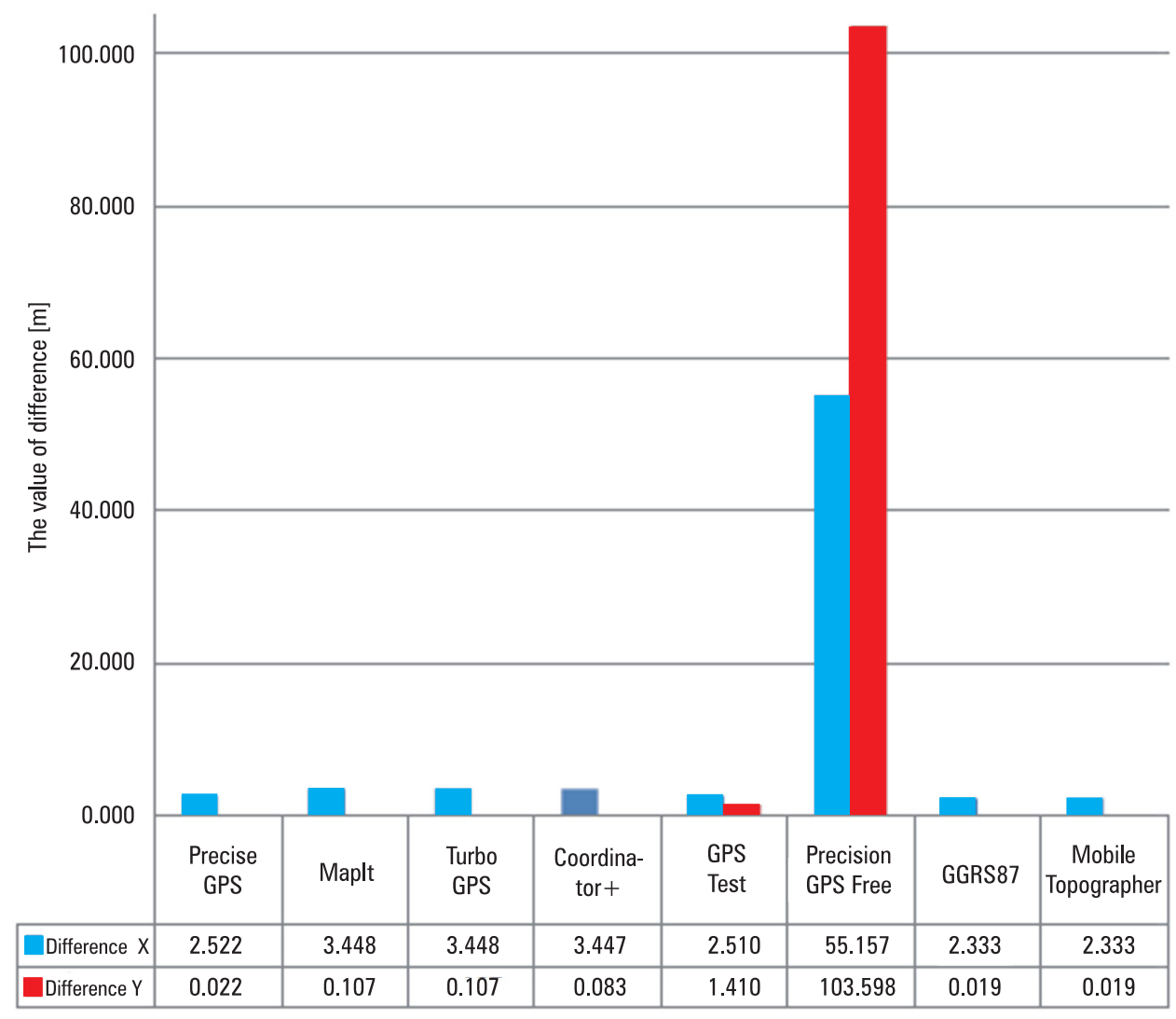

Fig. 3. Differences in measurements at point 2044

\subsubsection{Presentation of the mean value of differences in the measurements}

As follows from the diagram (Fig. 4), the largest mean differences occur on the $X$ coordinates. They range from about $2.000 \mathrm{~m}$ to as much as $19.300 \mathrm{~m}$. The best result was achieved by the Mobile Topographer application $(2.002 \mathrm{~m})$. The next best results came from the Precise GPS $(2.008 \mathrm{~m})$ and GPS Test $(2.009 \mathrm{~m})$ applications. MapIt and Turbo GPS applications obtained the same values at $2.161 \mathrm{~m}$, and Coordinator+ appli- 
cation followed them by three millimetres $(2.164 \mathrm{~m})$. The Precision GPS Free application obtained the worst result at $19.263 \mathrm{~m}$. The mean differences on $Y$ coordinates fell within the range of $0.500 \mathrm{~m}$ to $36.115 \mathrm{~m}$. The Precise GPS application presented the best result at $0.514 \mathrm{~m}$. Coordinator+ and Mobile Topographer applications have reached values equal to $0.524 \mathrm{~m}$, MapIt and Turbo GPS applications, $0.536 \mathrm{~m}$, and GPS Test application, $0.746 \mathrm{~m}$. The worst result was obtained using Precision GPS Free application, at $36.155 \mathrm{~m}$.

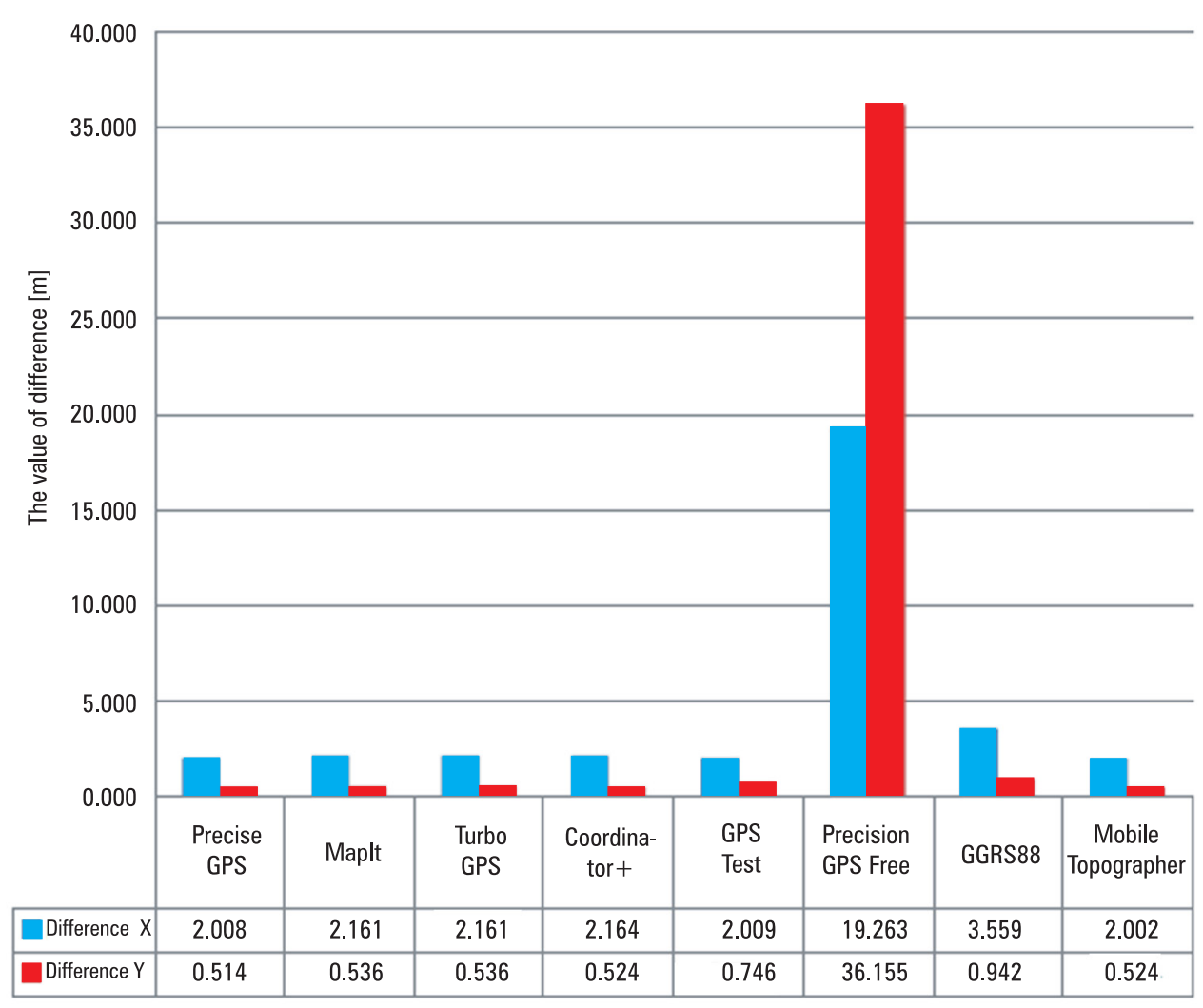

Fig. 4. Mean difference in the measurements

\section{Conclusions}

Smartphone applications make it possible to determine the position of the phone device with the same accuracy as the manual GPS receivers, i.e. with the accuracy of $\pm(1-3)$ metres. Thanks to this, we can effectively find objects whose coordinates are known.

This statement is based on the information in Figure 4, and the numbers contained in its lower section. 
Evidently, one of the applications (Precision GPS Free) shows considerable deviation from the others, in terms of large values of coordinate differences - also shown in Figure 4. We might say that these observations constitute outliers, and in accordance with the rules of the adjustment calculus they should be rejected when calculating average values - that is, the latter should be calculated only for the remaining pairs of differences.

Another conclusion related to this application is the recommendation to make a measurement check (control test) for coordinates at a reference point (or points) whose coordinates are known exactly. The result of that control measurement should verify the correct operation of the application.

An application that has passed such a control test can also be used in measurements for GIS purposes, among other things.

\title{
References
}

Kruszewski P. 2016. Nawigacja satelitarna w praktyce. Wydawnictwo i handel „KaBe”, Krosno. Kuboń N. 2017. Porównanie GPS z aplikacjami telefonicznymi. Praca dyplomowa, Uniwersytet Rolniczy w Krakowie.

Google Play 2016 i 2017. Aplikacje telefoniczne adresy internetowe w tekście pracy

\author{
Natalia Kuboń \\ Optima Spółka z o.o. \\ z siedzibą w Krakowie \\ ul. Na Błonie 32, Kraków \\ e-mail: natkub22@gmail.com \\ Dr inż. Marek Plewako \\ em. adiunkt w Katedrze Geodezji UR \\ ul. Balicka 253a; 30-198 Kraków \\ e-mail: rmplewak@cyf-kr.edu.pl
}

